Article

\title{
Hydrothermal Carbonization of Spent Osmotic Solution (SOS) Generated from Osmotic Dehydration of Blueberries
}

\author{
Kaushlendra Singh ${ }^{1, *}$ and Litha Sivanandan ${ }^{2}$
}

1 Division of Forestry and Natural Resources, Davis College of Agriculture, Natural Resources and Design, West Virginia University, 322 Percival Hall, P.O. Box 6125, Morgantown, WV 26506-6125, USA

2 West Virginia University Extension Service, West Virginia University, G-006 Agricultural Science Building, P.O. Box 6108, Morgantown, WV 26506-6108, USA;

E-Mail: Litha.Sivanandan@mail.wvu.edu

* Author to whom correspondence should be addressed; E-Mail: Kaushlendra.Singh@mail.wvu.edu; Tel.: +1-304-293-7643; Fax: +1-304-293-2441.

Received: 14 June 2014; in revised form: 20 August 2014 / Accepted: 23 August 2014 /

Published: 17 September 2014

\begin{abstract}
Hydrothermal carbonization of spent osmotic solution (SOS), a waste generated from osmotic dehydration of fruits, has the potential of transformation into hydrochars, a value-added product, while reducing cost and overall greenhouse gas emissions associated with waste disposal. Osmotic solution (OS) and spent osmotic solution (SOS) generated from the osmotic dehydration of blueberries were compared for their thermo-chemical decomposition behavior and hydrothermal carbonization. OS and SOS samples were characterized for total solids, elemental composition, and thermo-gravimetric analysis (TGA). In addition, hydrothermal carbonization was performed at $250{ }^{\circ} \mathrm{C}$ and for $30 \mathrm{~min}$ to produce hydrochars. The hydrochars were characterized for elemental composition, Brunauer-Emmett-Teller (BET) surface area, particle shape and surface morphology. TGA results show that the SOS sample loses more weight in the lower temperature range than the OS sample. Both samples produced, approximately, $40 \%-42 \%$ (wet-feed basis) hydrochar during hydrothermal carbonization but with different properties. The OS sample produced hydrochar, which had spherical particles of $1.79 \pm 1.30 \mu \mathrm{m}$ diameter with a very smooth surface. In contrast, the SOS sample produced hydrochar with no definite particle shape but with a raspberry-like surface.
\end{abstract}


Keywords: osmotic dehydration; fruit dehydration; blueberry; spent osmotic solution; hydrochar; hydrothermal carbonization; thermo-gravimetry; activation energy; carbon microspheres

\section{Introduction}

Osmotic dehydration of fruits (apple, cherry, blueberry, cranberry etc.) generates a liquid waste in the form of spent osmotic solutions (SOS), which needs to be disposed of in an environmentally benign manner. Osmotic dehydration is often used as an industrial process to reduce water activity (a measurement of the amount of water available for microbial growth), infuse solute into fruits to increase weight, and to dehydrate fruits. In the osmotic dehydration of fruits, solute (sugar) is mixed with water to prepare an osmotic solution (OS). The fruits are submerged into this osmotic solution under specific conditions of mass ratio of fruit:solution $\left(1: 10\right.$ to $1: 2$ [1]), temperature $\left(20-40{ }^{\circ} \mathrm{C}[1]\right)$ and vacuum (5 to $10 \mathrm{kPa}$ [2]) for a prescribed short period of time (15 min [2]) to facilitate water removal from fruit. After the prescribed period, partially dehydrated fruits are filtered out from the solution and placed in a dehydrator for further drying. The leftover solution is known as spent osmotic solution (SOS). Most of the industries reuse/recycle SOS several times but every time it is recycled, the solution becomes darker, lower in $\mathrm{pH}$, and richer in extractives (pectin, and acids) from the fruit being processed [1,3]. It also accumulates undesirable fungi and bacteria during processing and/or storage [1]. The SOS must be treated to regulatory standards before it can be discharged to land or surface/subsurface water [4].

Current procedures for handling waste from the fruit and vegetable industry are documented in the United States Environmental Protection Agency's document \# EPA-625/3-77-0007 [5]. The document explicitly explains wastewater treatment procedures. Similar regulatory documents are also adopted by various states. For example, the Michigan Department of Environmental Quality has documented its code and procedures under the title "Michigan Fruit and Vegetable Processor's Guide to Environmental Regulations" [6]. The fruit dehydration industry follows these regulatory standards for treating their waste. Currently, most of the fruit dehydration industries mix their spent osmotic solutions (SOS) with other wastewater, which includes leftover waste fruits, sanitizers/lubricants, waste from floor drains, etc. This wastewater is usually treated at either an onsite wastewater treatment facility or a Publicly Owned Treatment Works (POTW). It is expected that at the end of the wastewater treatment, the effluent would meet either surface or ground water discharge standards.

Federal and state regulations suggest use of a combination of physical, chemical and biological treatments to achieve the effluent limitations presented in the Table 1. Physical processes are screening, sedimentation (gravity settling) and filtration to remove large debris, grit and suspended solids. Chemical treatments are precipitation and chemical destruction systems to remove phosphorus. Biological treatments rely on living organisms to remove pollutants, particulates, and dissolved organic material from the wastewater. This includes processes such as waste-stabilization lagoons, trickling filters, rotating biological contactors, and activated sludge. Granholm and Chester [6] and the EPA [5] have documented all of the above processes in detail. 
Table 1. Potential Permit Limitations in the State of Michigan for effluent discharge into surface and ground water (Source: Granholm and Chester, [6]) and effluent limitations for BOD and Total Suspended Solids (TSS) (kg/1000kg of raw material processed) and for $\mathrm{pH}$ as listed in $40 \mathrm{CFR} \S 407$.

\begin{tabular}{|c|c|c|c|}
\hline \multirow[b]{2}{*}{ Indicator } & \multicolumn{2}{|c|}{ Potential Permit Limitations in the State of Michigan } & \multirow{2}{*}{$\begin{array}{l}\text { Effluent limitations } \\
\text { (40 CFR } § 407)\end{array}$} \\
\hline & $\begin{array}{l}\text { Limit for Surface } \\
\text { Water Discharge }\end{array}$ & $\begin{array}{l}\text { Limit for Ground } \\
\text { Water Discharge }\end{array}$ & \\
\hline $\begin{array}{l}\text { Biochemical Oxygen } \\
\text { Demand (BOD) }\end{array}$ & $\begin{array}{l}1.86 \mathrm{mg} / \mathrm{g} \text { of raw material } \\
\text { daily maximum (As listed } \\
\text { in } 40 \mathrm{CFR} \S 407)\end{array}$ & $\begin{array}{l}45 \mathrm{mg} / \mathrm{L} \text { daily maximum } \\
30 \mathrm{mg} / \mathrm{L} \text { monthly average }\end{array}$ & $\begin{array}{l}1.86 \mathrm{~kg} / 1000 \mathrm{~kg} \text { of raw } \\
\text { material processed daily } \\
1.13 \mathrm{~kg} / 1000 \mathrm{~kg} \text { monthly } \\
0.8 \mathrm{~kg} / 1000 \mathrm{~kg} \text { yearly }\end{array}$ \\
\hline Dissolved Oxygen & $\begin{array}{l}4.0 \text { to } 8.0 \mathrm{mg} / \mathrm{L} \text { (cold water) } \\
3.0 \text { to } 6.0 \mathrm{mg} / \mathrm{L} \text { (warm } \\
\text { water) }\end{array}$ & $\begin{array}{c}\text { No limit but lagoon should } \\
\text { maintain } 2.0 \mathrm{mg} / \mathrm{L} \text { to prevent odor }\end{array}$ & \\
\hline Nitrogen Compounds & $\begin{array}{l}0.5 \mathrm{mg} / \mathrm{L} \text { to } 30 \mathrm{mg} / \mathrm{L} \\
\text { (Ammonia) }\end{array}$ & $\begin{array}{c}5.0 \mathrm{mg} / \mathrm{L} \text { (total inorganic nitrogen) } \\
\text { With } 0.5 \mathrm{mg} / \mathrm{L} \text { (nitrite limitation) }\end{array}$ & \\
\hline $\begin{array}{l}\text { Total Suspended } \\
\text { Solids }\end{array}$ & (As listed in 40 CFR 407) & - & $\begin{array}{l}3.34 \mathrm{~kg} / 1000 \mathrm{~kg} \text { of raw } \\
\text { material processed daily } \\
2.32 \mathrm{~kg} / 1000 \mathrm{~kg} \text { monthly } \\
1.48 \mathrm{~kg} / 1000 \mathrm{~kg} \text { yearly }\end{array}$ \\
\hline $\begin{array}{l}\text { Total Dissolved } \\
\text { Solids (In-stream } \\
\text { after discharge) }\end{array}$ & $\begin{array}{l}750 \mathrm{mg} / \mathrm{L} \text { as a daily } \\
\text { maximum } 500 \mathrm{mg} / \mathrm{L} \text { as a } \\
\text { monthly average }\end{array}$ & no standards & \\
\hline Phosphorus & $1 \mathrm{mg} / \mathrm{L}$ & $\begin{array}{c}1 \mathrm{mg} / \mathrm{L} \text { at } 1000 \text { feet away from } \\
\text { surface water }\end{array}$ & \\
\hline $\mathrm{pH}$ & 6.5 to 9.0 & 6.5 to 9.0 & 6.0 to 9.5 \\
\hline
\end{tabular}

While the final destiny of SOS is to dispose of it in a wastewater treatment facility, several management practices have been suggested to minimize its generation in the first place $[1,4]$. In addition, extractions of value-added compounds from certain fruit processing waste have also been proposed $[3,7,8]$. Since sugar-based SOS is the main source of Biochemical Oxygen Demand (BOD), it is highly recommended to reduce its generation through optimization of the osmotic dehydration process and recycling of SOS several times. Current industrial osmotic dehydration processes involve submerging fruit into osmotic solutions to dewater the fruit. For these processes, the approximate food-to-solution ratio is recommended to be 1:5 to maintain fruit dewatering capacity of the solution [1]. However, technical breakthroughs in new process equipment may actually reduce solution consumption to a ratio of 1:2. During dehydration, aromas, pigments, acids and proteins are leached from fruits into the SOS, which changes the chemical (organic matter), physical ( $\mathrm{pH}$, water activity, and viscosity), and sensory (color and flavor) characteristics of the SOS. Repeated use of the SOS results in darkening of the solution and degradation in the antioxidant content. Additionally, leaching of organic acids from fruit to solution reduces the $\mathrm{pH}$ from 6.0 to 4.0. Before repeated use, the SOS are concentrated by a combination of the following processes: evaporation, solute addition, membrane concentration, and cryoconcentration. However, controlling microbial contamination during SOS reuse is always a challenge. Research suggests that the concentrated spent solution must be sanitized in order to reduce 
the Coliform bacteria to 12000 (total) and 12000 (fecal) and Streptococcus faecalis to 2000 CFU (Colony Forming Units)/100 mL [1].

SOS from fruit dehydration, which can no longer be recycled, are sometimes used for other food preparations, for example, syrup for fruit canning, fruit jams, additives to fruit juices and soft drinks, and as a source of by-products (flavoring). Several studies on the extraction of by-products have been reported [3,7-9]. Blueberry waste, to be specific, has been used to extract anthocyanins and polyphenolics at a lab-scale using various methods. For example, Paes et al. [7] used supercritical $\mathrm{CO}_{2}$ and pressurized water whereas Nicoué et al. [9] used ethanol to extract anthocynanins. Lee and Wrolstad [8] used citric acid, $\mathrm{SO}_{2}$, and enzymes to extract polyphenolics and anthocynanins. Nevertheless, none of these processes achieved commercial success and SOS is currently considered as waste.

While biological treatment of industrial waste has been considered acceptable practice since the dawn of environmental regulations, significant technical breakthroughs in other thermochemical technologies, for example, pyrolysis, gasification, and hydrothermal liquefaction/carbonization, have the potential to not only reduce waste and greenhouse gas (GHG) emissions but also generate valuable bioproducts in a very short reaction time. Hydrothermal carbonization is defined as a mild form of pyrolysis using an aqueous feedstock [10]. During hydrothermal carbonization, biomass is treated in hot compressed water yielding three product forms: solid hydrochar, aqueous compounds, and gases [10]. Gupta et al. [11] state that hydrothermal carbonization is generally performed by heating biomass in subcritical water at $230-350{ }^{\circ} \mathrm{C}$ and 3.48 to $20.68 \mathrm{MPa}$ to obtain insoluble carbon-rich (hydrochar) and water-soluble products (biocrude). A review article authored by Libra et al. [12] states that hydrothermal carbonization processes are performed up to process temperatures of $220{ }^{\circ} \mathrm{C}$ and corresponding pressures of up to approximately $2 \mathrm{MPa}$ to transform organics into solid hydrochar and very little gases (1\%-5\%). In another review, Funke and Ziegler [13] define hydrothermal carbonization as a combination of dehydration and decarboxylation reactions which are achieved by applying temperatures of $180-200{ }^{\circ} \mathrm{C}$ in a suspension of biomass and water at saturated pressure for several hours. It may seem that Gupta et al. [11], Libra et al. [12], and Funke and Ziegler [13] reported different temperature and pressure conditions for hydrothermal carbonization; however, in all three cases water is kept in subcritical condition. Subcritical water is also called pressurized hot water, compressed hot water, or superheated water [14]. Subcritical water is hot water maintained in the liquid state at temperatures between $100{ }^{\circ} \mathrm{C}$ and $374{ }^{\circ} \mathrm{C}$ under pressurized conditions. The critical temperature and pressure of water are $374{ }^{\circ} \mathrm{C}$ and $22.4 \mathrm{MPa}$, respectively [14]. Wiboonsirikul and Adachi [14] report that physiochemical properties of water, in particular its relative dielectric constant and ion product, change with increasing temperature. The ion product of water is defined as the product of the concentrations of hydrogen and hydroxyl ions [14]. The relative dielectric constant, ability to dissolve both polar and non-polar substances, of water decreases from 80 at $25^{\circ} \mathrm{C}$ to 27 at $250{ }^{\circ} \mathrm{C}$ [14]. For comparison, solvents like methanol and ethanol have dielectric constants of 33 and 24 , respectively, at $25^{\circ} \mathrm{C}$ [14]. Therefore, under subcritical conditions, hot compressed water develops an ability to dissolve natural compounds, such as phenolic, polycyclic aromatic compounds, and oils [14] due to its low dielectric constant. In addition, it acts as acidic or basic catalysts due to, approximately, threefold higher dissociation constant for hydrogen and hydroxyl ions than normal water. Finally, subcritical water has a higher diffusion 
coefficient for solutes and a low viscosity and surface tension, which promote more mass transfer and penetration ability [14].

While solid hydrochar is main product of hydrothermal carbonization, another process known as hydrothermal liquefaction is more geared towards the production of liquid biocrude [15,16]. Toor et al. [15] state that hydrothermal liquefaction is carried out at $280-370{ }^{\circ} \mathrm{C}$ and between 10 and $25 \mathrm{MPa}$. It should be noted that both hydrothermal carbonization and hydrothermal liquefaction have overlapping operating conditions of temperature and pressure. Therefore, similar conditions of temperature and pressure might create hydrothermal carbonization reactions (dehydration and decarboxylation) for one type of feedstock and hydrothermal liquefaction reactions (complete degradation of feedstock into different chemical compounds) for another feedstock. For example, hydrothermal carbonization of glucose has been reported under $170{ }^{\circ} \mathrm{C}$ to $240{ }^{\circ} \mathrm{C}$ [17] whereas its liquefaction has been reported between $300{ }^{\circ} \mathrm{C}$ to $400{ }^{\circ} \mathrm{C}$ and 25 to $40 \mathrm{MPa}$ [15]. Similarly, hydrothermal carbonization of fructose has been reported between $120{ }^{\circ} \mathrm{C}$ to $140{ }^{\circ} \mathrm{C}$ [18] whereas its liquefaction has been reported between $200{ }^{\circ} \mathrm{C}$ to $320{ }^{\circ} \mathrm{C}$ [15]. Therefore, process conditions of subcritical water together with the thermo-chemical decomposition behavior of the feedstock decide whether reaction conditions fall into hydrothermal liquefaction or carbonization.

The feedstock of interest in this study is SOS, a waste generated from osmotic dehydration of fruits. Hydrothermal carbonization has been extensively studied [19,20] for treatment of wastewater and sludge. Shanableh [20] reports complete removal of chemical oxygen demand as a result of hydrothermal treatment of municipal sludge. Hydrothermal carbonization of municipal sludge from the food industry not only retains $75 \%$ of the feedstock carbon in the hydrochar but also generates wastewater rich in hydrolysis products with chemical oxygen demand, total organic carbon, and $\mathrm{pH}$ similar to the landfill leachate [19]. Literature review reveals that the product of interest, hydrochar, generated from hydrothermal carbonization of sugar rich feedstock, collectively known as saccharides, is more valuable than that generated from treatment of municipal sludge. For example, hydrochars, which are also referred as carbon microspheres, were produced from hydrothermal carbonization of saccharides [17,18,21-23]. To avoid confusion, the term "carbon microspheres" refers to hydrochars with various volatiles present at their surface and in their core, whereas term "carbon microparticles" refers to pure carbon free of volatiles. Carbon microspheres (hydrochar) produced from pure compounds have shown promise in nano-applications. Some researchers went a step further and tailored hydrochars into core/shell nanoparticles for optical nano-devices [24,25] nano-fibers [26,27] and nano-cables/nanotubes [28,29]. While pure saccharides have been used to produce carbon microspheres, no work has been reported on studying the thermo-chemical decomposition behavior of SOS and analyzing hydrochars produced from hydrothermal carbonization of SOS. SOS contains some acids, antioxidants, and soluble fiber, which should generate valuable carbon microspheres (hydrochars) with different morphology. Therefore, the main objectives of this research were the following:

1. to compare the thermo-chemical decomposition behavior of osmotic solution (OS) and spent osmotic solution (SOS) generated from osmotic dehydration of blueberries; and

2. to compare hydrochar yields and properties produced during hydrothermal carbonization of SOS and OS. 
It was anticipated that hydrothermal carbonization of SOS would follow a reaction pattern similar to the one reported for the mixture of glucose and acrylic acid [23], proteins [30] and orange juice [21]. Therefore, this research evaluates hydrothermal carbonization of SOS to produce carbon microspheres (hydrochar), carbon microparticles, and other valuable products.

\section{Results and Discussion}

\subsection{Feed Characteristics}

Osmotic solution prepared at $65^{\circ} \mathrm{Brix}$ had $66.25 \%$ total solids (TS) and a pH of 6.61 , while the SOS sample had $59.00 \%$ TS and a $\mathrm{pH}$ of 3.61 . The TS decreased due to movement of water from the blueberries to the osmotic solution and movement of sugar from the osmotic solution to the blueberries. Additionally, elemental analysis of freeze-dried SOS and OS samples (Table 2) showed that both samples had statistically similar elemental composition. In addition, both samples had similar higher heating values, approximately $21 \mathrm{MJ} / \mathrm{kg}$.

Table 2. Elemental analysis and higher heating values (HHV) of freeze-dried SOS, OS, glucose, and sucrose samples.

\begin{tabular}{ccccc}
\hline Sample Type & Freeze-dried SOS & Freeze-dried OS & Glucose [17] & Sucrose [17] \\
\hline $\mathrm{C}($ weight \%) & $42.35 \pm 0.57^{\mathrm{a}}$ & $42.22 \pm 0.08^{\mathrm{a}}$ & 40.00 & 42.11 \\
$\mathrm{H}($ weight \%) & $8.95 \pm 0.22^{\mathrm{a}}$ & $9.14 \pm 0.06^{\mathrm{a}}$ & 6.67 & 6.43 \\
$\mathrm{O}($ weight \%) & $47.83 \pm 0.69^{\mathrm{a}}$ & $47.08 \pm 0.03^{\mathrm{a}}$ & 53.33 & 51.46 \\
$\mathrm{O} / \mathrm{C}($ Atomic) & $0.85 \pm 0.02^{\mathrm{a}}$ & $0.82 \pm 0.00^{\mathrm{a}}$ & 1.00 & 0.92 \\
$\mathrm{H} / \mathrm{C}($ Atomic) & $2.53 \pm 0.03^{\mathrm{a}}$ & $2.54 \pm 0.01^{\mathrm{a}}$ & 2.00 & 1.83 \\
$\mathrm{HHV}(\mathrm{MJ} / \mathrm{kg})$ & $20.43 \pm 0.55^{\mathrm{a}}$ & $21.03 \pm 0.10^{\mathrm{a}}$ & & \\
\hline
\end{tabular}

Note: Numbers followed by similar letter, "a" for example, in a row are not statistically significant $(p$-value $>0.05) . \mathrm{HHV}=0.3491 \mathrm{C}+1.1783 \mathrm{H}+0.1005 \mathrm{~S}-0.1034 \mathrm{O}-0.0151 \mathrm{~N}[31]$.

ATR-IR spectra of freeze-dried OS and SOS, provided in the supplemental information, were compared in three wavenumber regions: (1) from $3600 \mathrm{~cm}^{-1}$ to $3000 \mathrm{~cm}^{-1}$; (2) from $3000 \mathrm{~cm}^{-1}$ to $2750 \mathrm{~cm}^{-1}$; and (3) from $1700 \mathrm{~cm}^{-1}$ to $1550 \mathrm{~cm}^{-1}$. Region-1 is expected to show absorbance peaks for intermolecular dimeric and polymeric bonded $\mathrm{OH}$. Region-2 is expected to show absorbance peaks for $\mathrm{C}-\mathrm{H}$ and region-3 is expected to show absorbance peaks for $\mathrm{C}=\mathrm{O}, \mathrm{C}=\mathrm{C}$ [32].

The key observation was that the SOS sample had one smooth arch starting from $3650 \mathrm{~cm}^{-1}$, with the highest peak located at $3250 \mathrm{~cm}^{-1}$, and ending at $3000 \mathrm{~cm}^{-1}$. In contrast, the OS sample also had an arc in the same wavenumber range but it had two extra spikes, one at $3550 \mathrm{~cm}^{-1}$ and another at $3400 \mathrm{~cm}^{-1}$ besides the highest peak similar to the SOS sample. The first additional peak was associated with the $\mathrm{OH}$ bonding present in fructose and the second additional peak was associated with the $\mathrm{OH}$ bonding present in glucose molecules. This fact was verified by taking ATR-IR spectra for pure D-fructose and D-glucose samples. Sugar or sucrose, also known as table sugar, is generally extracted from either sugarcane or sugar beet and it is more than $99 \%$ sucrose. A molecule of sugar is made-up of a glucose and a fructose unit. Therefore, spectra of the sucrose sample had signatures of both fructose and glucose. Both additional peaks disappeared in the ATR-IR spectrum of SOS, which showed that the crystalline structure of the 
SOS was very different from that of the OS sample. In the second region, the absorption peak for $\mathrm{C}-\mathrm{H}$ bonding $\left(>\mathrm{CH}_{2}\right)$ was larger and smoother in the SOS sample than the OS sample. Similarly, region-3 peaks were larger for the SOS sample than the OS sample. These are the two regions where Anthocyanin (antioxidant) shows its signature peaks [33].

\subsection{Thermo-chemical Decomposition Behavior}

Figure 1a shows the relationship between weight loss and temperature as obtained from the thermo-gravimetric analysis for the freeze-dried SOS and $65^{\circ}$ Brix osmotic solution. At the end of the heating at $600{ }^{\circ} \mathrm{C}$, the SOS sample produced $19.27 \%$ residue char, whereas the other sample produced $17.00 \%$ residue char. This could be possibly due to the presence of more fibers and other extractives (pectin, and acids) transferred from the blueberries in the SOS [1]. Table 3 presents the residual char yield and weight loss observed in four temperature zones $\left(120-160{ }^{\circ} \mathrm{C} ; 180-250{ }^{\circ} \mathrm{C}, 250-350{ }^{\circ} \mathrm{C}\right.$, and $350-600^{\circ} \mathrm{C}$ ) during the TGA experiments performed at a heating rate of $10^{\circ} \mathrm{C} / \mathrm{min}$.

Figure 1. (a) Loss of samples weight (b) rate of fractional conversion (c) activation energy as a function of fractional conversion of thermo-chemical decomposition under nitrogen atmosphere of freeze-dried osmotic solution and spent osmotic solution (SOS) generated from osmotic dehydration of blueberries.

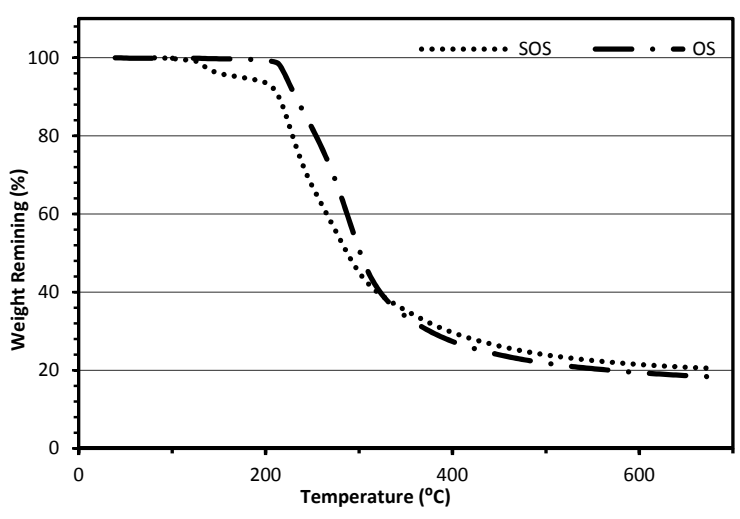

(a)

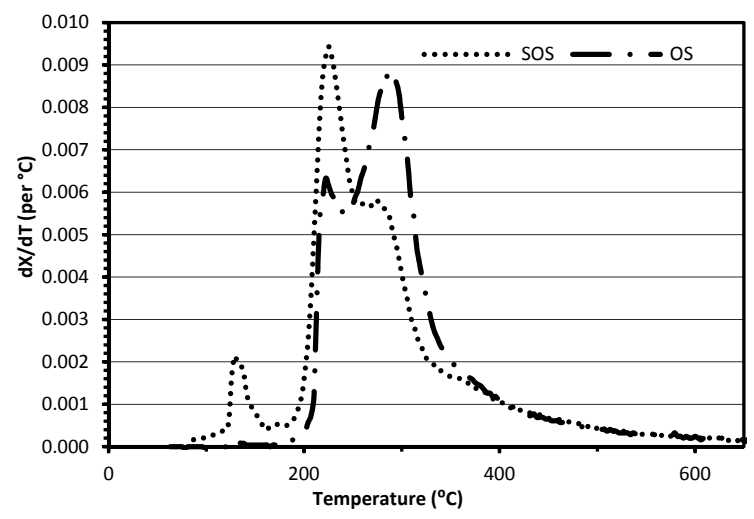

(b)

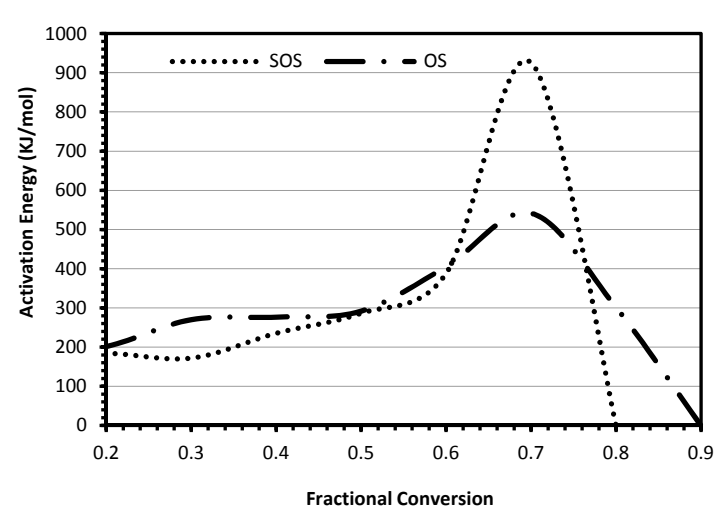

(c)

In the $120-160^{\circ} \mathrm{C}$ temperature zone, the OS sample showed very little decomposition compared to the SOS sample, which lost approximately $4 \%$ of its weight in this temperature zone, possibly due to decomposition of antioxidants present in the SOS sample. Khanal et al. [34] reported that heating dried 
blueberries up to $125{ }^{\circ} \mathrm{C}$ resulted in more than $52 \%$ loss of antioxidants. In the $180-250{ }^{\circ} \mathrm{C}$ temperature zone, mostly fructose and some glucose decompose. In this zone, the SOS sample lost $30 \%$ of the mass compared to $19 \%$ weight loss of the OS sample. Finally, in the third zone $\left(250-300{ }^{\circ} \mathrm{C}\right)$, the OS sample lost $47 \%$ of weight compared to $18 \%-20 \%$ weight loss of the SOS sample. Figure $1 \mathrm{~b}$ is the derivative of Figure 1a, also called dtg graph. The dtg graph is plotted as the rate of fractional conversion $v s$. temperature. The dtg graph shows the presence of two peaks for the OS sample and the presence of three peaks for the SOS sample. In the SOS sample, the first peak occurred at $130^{\circ} \mathrm{C}$, the second peak occurred at $225{ }^{\circ} \mathrm{C}$, and the third peak occurred at $280{ }^{\circ} \mathrm{C}$. In contrast, the OS sample has peaks at $225{ }^{\circ} \mathrm{C}$ and $280^{\circ} \mathrm{C}$. The first peak in the SOS sample was probably due to the decomposition of antioxidants [34]. The other two peaks were due to the decomposition of two dominant chemical compounds (sucrose, glucose, or fructose, etc.) present in both SOS as well as the osmotic solution. When comparing the dtg graphs of the osmotic solution sample with the SOS sample, it is very clear that the rate of decomposition was very large at $225^{\circ} \mathrm{C}$ for the SOS sample.

Figure 1c shows the activation energy, calculated using the isoconversion method [35], as a function of fractional conversion for chemical reactions taking place during the TGA experiments. The OS sample has two activation energy peaks at the fractional conversion of 0.3 and 0.7 , whereas the SOS sample has only one activation energy peak at the fractional conversion of 0.7 . The activation energy of the OS sample was $270 \mathrm{~kJ} / \mathrm{mol}$ at the fractional conversion of 0.3 and the decomposition temperature of $260^{\circ} \mathrm{C}$. At the same fraction conversion of 0.3 , the activation energy of the SOS sample was $172 \mathrm{~kJ} / \mathrm{mol}$, which occurred at $235{ }^{\circ} \mathrm{C}$. The activation energy of the OS sample was $542 \mathrm{~kJ} / \mathrm{mol}$ at the fractional conversion of 0.7 , which took place at the temperature of $315^{\circ} \mathrm{C}$.

Table 3. Average residual char yield and weight loss observed in various temperature zones during TGA analysis of freeze-dried osmotic solution (OS) and SOS samples generated from blueberry dehydration.

\begin{tabular}{ccccc}
\hline \multicolumn{2}{c}{ Sample } & & SOS & OS \\
\cline { 1 - 2 } Average Residual Char $(\%)$ & & $19.27 \pm 1.37$ & $17.00 \pm 1.18$ \\
\hline \multicolumn{2}{c}{ Temperature Zones $\left({ }^{\circ} \mathbf{C}\right)$} & Heating Rates $\left({ }^{\circ} \mathbf{C} / \mathbf{m i n}\right)$ & Percent Weight loss in Various Temperature Zones \\
\cline { 1 - 2 } $120-160$ & 10 & 3.86 & 0.18 \\
$180-250$ & 10 & 28.66 & 18.76 \\
$250-350$ & 10 & 30.90 & 47.29 \\
$350-600$ & 10 & 13.66 & 14.18 \\
\hline
\end{tabular}

\subsection{Hydrothermal Carbonization}

\subsubsection{Product Yields}

Table 4 shows hydrochar, liquid, and gas yields from the hydrothermal carbonization of the SOS and OS samples. On a wet-feed basis, the SOS and OS samples produced hydrochar yields of $40.09 \%$, and $42.01 \%$, respectively. Similarly, on the dry-feed matter basis, the SOS and OS samples produced $63.41 \%$ to $67.96 \%$ hydrochar and $18.40 \%$ to $23.57 \%$ liquids, which was higher than the residual char yields reported in the TGA experiments (Table 3) due to different reaction conditions (hydrothermal 
carbonization versus pyrolysis). However, TGA results may very well be used to understand how samples behave under heating at different temperatures. The thermal decomposition behavior observed in the TGA explains (Table 3) that the major weight loss for the OS and SOS samples takes place after the $250{ }^{\circ} \mathrm{C}$. Therefore, temperatures above $250{ }^{\circ} \mathrm{C}$ might be required for complete carbonization of the samples. Additionally, the char yield in the TGA experiments represents the weight of volatile-free char whereas the hydrochar yield includes both the weight of residual carbon plus the condensed volatiles. In the literature, Sevilla and Fuertes [17] have reported hydrochar yield of 37\%, when one mol/liter glucose solution was processed at $240{ }^{\circ} \mathrm{C}$ for $30 \mathrm{~min}$. Others reported hydrochar yields are $63.00 \%$ for cellulose processed at $225{ }^{\circ} \mathrm{C}$ for $3 \mathrm{~h} ; 50.70 \%$ for wood processed at $250{ }^{\circ} \mathrm{C}$ for $72 \mathrm{~h}$; and $60.00 \%$ for swine manure and chicken litter processed at $250{ }^{\circ} \mathrm{C}$ for $20 \mathrm{~h}$ [12]. According to Sevilla and Fuertes [17], hydrochar yield was influenced by processing time, glucose concentration, and processing temperature when hydrothermal carbonization was performed in a pressure vessel. For example, hydrochar yield increased from $37 \%$ to $43 \%$ when processing time was increased from 30 min to $1 \mathrm{~h}$ while keeping processing temperature at $240{ }^{\circ} \mathrm{C}$ and glucose concentration at $1 \mathrm{~mol} / \mathrm{L}$. Similarly, hydrochar yield increased from $31 \%$ to $43 \%$ when processing temperature was raised from 230 to $240{ }^{\circ} \mathrm{C}$ while keeping glucose concentration at $1 \mathrm{~mol} / \mathrm{L}$ and processing time at $1 \mathrm{~h}$. Gas and liquid yields were not significantly different for the two samples. These findings are in agreement with those shown in Table 4.

Table 4. Average yield (mean $\pm \mathrm{SD}$, replications $=3$ ) of moisture-free hydrochar, liquid, and gas products, on wet-feed basis and on dry-feed basis, from hydrothermal treatment $\left(250{ }^{\circ} \mathrm{C}\right.$ for $30 \mathrm{~min}$ ) of OS and SOS samples generated from blueberry dehydration.

\begin{tabular}{ccccccc}
\hline & \multicolumn{3}{c}{ Product Yields (on wet-feed basis) } & \multicolumn{3}{c}{ Product Yields (on dry-feed matter basis) } \\
\hline Sample & Hydrochar (\%) & Liquids (\%) & Gasses (\%) & Hydrochar (\%) & Liquids (\%) & Gasses (\%) \\
\hline SOS & $40.09 \pm 1.42^{\text {a }}$ & $51.86 \pm 1.45^{\text {a }}$ & $8.05 \pm 0.88^{\text {a }}$ & $67.96 \pm 2.41^{\text {a }}$ & $18.40 \pm 2.46^{\text {a }}$ & $13.65 \pm 1.49^{\text {a }}$ \\
OS & $42.01 \pm 2.03^{\text {a }}$ & $49.37 \pm 2.91^{\text {a }}$ & $8.63 \pm 2.85^{\text {a }}$ & $63.41 \pm 3.07^{\text {a }}$ & $23.57 \pm 4.40^{\text {a }}$ & $13.02 \pm 4.31^{\text {a }}$ \\
\hline
\end{tabular}

Note: Numbers followed by similar letter; "a" for example, in a column are not statistically significant ( $p$-value $>0.05)$.

Additionally, the yield of hydrochar produced from hydrothermal carbonization of saccharides is influenced by the type saccharide [17]. In fact, the type of saccharide directly affects the mechanism of hydrochar formation. In-depth chemistry has not been established for the formation of carbon microspheres; however, plausible explanations are available in the literature $[17,18]$ to explain differences in the formation of carbon microspheres (hydrochar) from various saccharides.

The molecular structure of saccharides (sucrose, fructose, glucose, and starch) governs the mechanism of carbon microsphere formation. Among the mentioned saccharides, fructose and glucose are monosaccharide but there is a fundamental difference in their molecular structure. Sucrose is a disaccharide made-up of a glucose and a fructose unit.

Sevilla and Fuertes [17] described the chemistry of microsphere formation during hydrothermal carbonization. According to them, sucrose undergoes hydrolysis forming individual monosaccharaides (glucose and fructose). Simultaneous dehydration and fragmentation (i.e., ring opening and $\mathrm{C}-\mathrm{C}$ bond breaking) of glucose and fructose occurs. Decomposition of monosaccharaides leads to formation of organic acids (acetic, lactic, propionic, levulinic, and formic acids) resulting in a rapid decrease in $\mathrm{pH}$. Dehydrated monomers and their decomposition products undergo polymerization and condensation 
forming carbon microspheres. Sevilla and Fuertres [17] reported a core-shell structure of the microspheres. The hydrophobic core was made up of aromatic oxygen forming compounds (ether, quinone, pyrone, etc.) while the hydrophilic shell was made up of high-density reactive oxygen functional groups (hydroxyl, phenolic, carbonyl, etc.).

\subsubsection{Gas Composition}

Table 5 shows gas composition of gaseous products generated from hydrothermal treatment of SOS and OS samples.

Table 5. Average (mean $\pm \mathrm{SD}$, replications $=3$ ) gas composition of gaseous products generated during hydrothermal treatment $\left(250^{\circ} \mathrm{C}\right.$ for $\left.30 \mathrm{~min}\right)$ of OS and SOS generated from blueberry dehydration.

\begin{tabular}{ccccc}
\hline Sample & Hydrogen (\%) & Carbon Dioxide (\%) & Oxygen (\%) & Carbon Monoxide (\%) \\
\hline SOS & $1.86 \pm 0.14^{\mathrm{a}}$ & $63.45 \pm 0.49^{\mathrm{a}}$ & $0.12 \pm 0.11^{\mathrm{a}}$ & $6.97 \pm 0.52^{\mathrm{a}}$ \\
Osmotic Solution & $1.57 \pm 0.61^{\mathrm{a}}$ & $52.60 \pm 0.43^{\mathrm{b}}$ & $2.60 \pm 2.82^{\mathrm{a}}$ & $6.91 \pm 0.26^{\mathrm{a}}$ \\
\hline
\end{tabular}

Note: Numbers followed by similar letter; "a" for example, in a column are not statistically significant $(p$-value $>0.05)$.

All but the carbon dioxide contents were similar for both samples. The carbon dioxide was $63.45 \%$ for the SOS sample decomposition, which was significantly higher than the $52.60 \%$ carbon dioxide of the osmotic sample decomposition $(p$-value $<0.001)$. The high carbon dioxide content during SOS decomposition is possibly due to decomposition of antioxidants that took place below 120 to $160{ }^{\circ} \mathrm{C}$ (Table 3). Khanal et al. [34] report that most of the antioxidants in blueberries were degraded at around $125^{\circ} \mathrm{C}$.

\subsubsection{Hydrochar Properties}

Hydrochars produced from the osmotic solution and SOS had no ash and approximately 54\% fixed carbon and $47 \%$ volatile matter content. The volatile matter corresponds to chemical functionalities, which are removed during the production of carbon microparticles. In addition, elemental analysis shows that the hydrothermal process transformed SOS with $42.35 \%$ total carbon content (moisture free basis) (Table 2) into hydrochar with $69.96 \%$ total carbon content (Table 6). At the same time, the hydrogen content dropped from $8.95 \%$ (Table 2) to $6.07 \%$ (Table 6 ) and oxygen content reduced from $47.83 \%$ (Table 2) to $23.56 \%$ (Table 6). The changes in carbon, hydrogen, and oxygen contents are consistent with a carbonization process. The ash content was measured to be zero for the OS and SOS hydrochars. The equipment TGA 701 with balance resolution of $0.00001 \mathrm{~g}$ and precision of $0.02 \%$ RSD with ASTM D3174 standard was used for these measurements.

The carbon microspheres (hydrochars) had carbon contents of approximately $65 \%$ with $\mathrm{O} / \mathrm{C}$ and $\mathrm{H} / \mathrm{C}$ ratios higher than coal [17]. Carbon balance showed that $64.85 \% \pm 2.09 \%$ of the carbon present in the SOS was retained in the hydrochar, whereas $66.64 \% \pm 3.27 \%$ of the carbon present in the OS was retained in respective hydrochar. According to the literature, depending on the type of saccharide and operating conditions (feedstock, concentration, temperature, and reaction time), between $2.4 \%$ (glucose, 
$0.50 \mathrm{~mol} / \mathrm{L}, 170{ }^{\circ} \mathrm{C}$, and $4.5 \mathrm{~h}$ ) to $46.4 \%$ (glucose, $1 \mathrm{~mol} / \mathrm{L} .210^{\circ} \mathrm{C}$, and $4.5 \mathrm{~h}$ ) of the carbon contained in the saccharide was retained in the hydrochar [17].

Table 6. Elemental and proximate analyses, higher heating values (HHV), and Brunauer-Emmett-Teller (BET) surface area of hydrochars made from SOS, OS, glucose and sucrose samples. The BET surface area was measure for devolatilized hydrochars only.

\begin{tabular}{lcccc}
\hline Sample Type & SOS Hydrochar & OS Hydrochar & Glucose Hydrochar [17] & Sucrose Hydrochar [17] \\
\hline C (weight \%) & $69.96 \pm 1.53^{\mathrm{a}}$ & $70.53 \pm 1.74^{\mathrm{a}}$ & 66.29 & 65.02 \\
$\mathrm{H}($ weight \%) & $6.07 \pm 0.16^{\mathrm{a}}$ & $6.08 \pm 0.10^{\mathrm{a}}$ & 4.15 & 4.21 \\
O (weight \%) & $23.56 \pm 1.60^{\mathrm{a}}$ & $23.01 \pm 1.85^{\mathrm{a}}$ & 29.56 & 30.77 \\
O/C (Atomic) & $0.25 \pm 0.02^{\mathrm{a}}$ & $0.25 \pm 0.03^{\mathrm{a}}$ & 0.33 & 0.36 \\
H/C (Atomic) & $1.04 \pm 0.01^{\mathrm{a}}$ & $1.03 \pm 0.03^{\mathrm{a}}$ & 0.83 & 0.78 \\
Volatile Matter (\%) & $46.76 \pm 0.32^{\mathrm{a}}$ & $48.72 \pm 2.76^{\mathrm{a}}$ & & \\
Fixed Carbon (\%) & $53.69 \pm 0.33^{\mathrm{a}}$ & $51.35 \pm 2.62^{\mathrm{a}}$ & & \\
Ash (\%) & $0^{\mathrm{a}}$ & $0^{\mathrm{a}}$ & & \\
Carbon Yield $(\%)$ & $64.85 \pm 2.09^{\mathrm{a}}$ & $66.64 \pm 3.27^{\mathrm{a}}$ & 46.4 & 3.00 \\
HHV (MJ/kg) & $29.78 \pm 0.85^{\mathrm{a}}$ & $29.79 \pm 0.75^{\mathrm{a}}$ & & $6.0 \pm 2.1$ \\
BET Surface Area $\left(\mathrm{m}^{2} / \mathrm{g}\right)$ & $49.06^{*}$ & $16.62^{*}$ & 3.00 & $1.0 \pm 0.1$ \\
Sphere diameter $(\mu \mathrm{m})$ & Amorphous & $1.79 \pm 1.30$ & & \\
\hline
\end{tabular}

Note: Numbers followed by similar letter; "a" for example, in a row are not statistically significant ( $p$-value $>0.05)$; * Devolatilization of hydrochars was performed by heating the hydrochars in the crucibles of LECO TGA 701 up to $600{ }^{\circ} \mathrm{C}$ for 30 min under nitrogen condition.

\subsubsection{Hydrochar Structural Characteristics}

Hydrothermal carbonization of SOS and OS generated hydrochars with varying structural characteristics of particle shape, hydrochar microsphere diameter, BET surface area, and surface morphology. Figure 2 shows SEM images of the changes in surface morphology of OS (Figure 2a), when it was transformed into SOS (Figure 2b), and then into hydrochar (Figure 2c). Comparison of Figure 2a,b reveals that the freeze-dried SOS has a smooth coating of blueberry extract on its surface. Comparison of Figure $2 b, c$ shows that the hydrothermal carbonization process created a highly porous carbon surface.

Figure 2. SEM pictures of (a) freeze-dried osmotic sugar solution (b) freeze-dried SOS and (c) hydrochar made from SOS through hydrothermal carbonization at $250{ }^{\circ} \mathrm{C}$ with 30 min of reaction time.

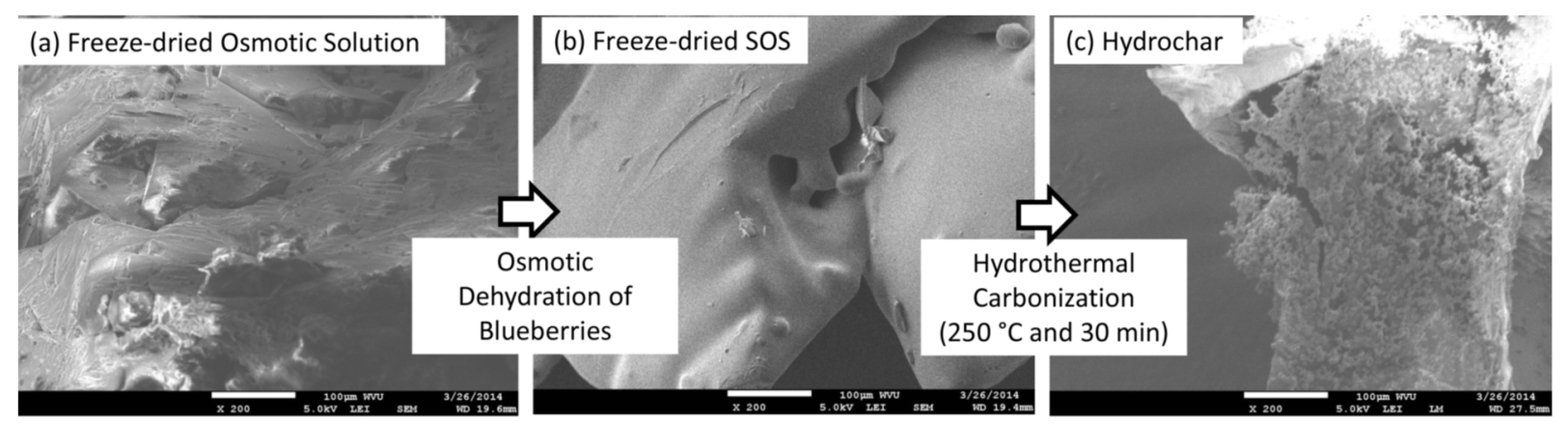


Hydrochars produced from OS were mostly spherical in shape with an average diameter of $1.79 \pm 1.30 \mu \mathrm{m}$ (Figure 3). Figure 3 shows transformation of the crystalline surface of OS into spherical particles of varying diameters due to carbonization. Of the 50 spherical particles measured for diameter, approximately, 20 particles had diameters ranging from 0.47 to $0.94 \mu \mathrm{m} ; 14$ particles had diameters ranging from 1.00 to $1.75 \mu \mathrm{m}$; and remaining 16 particles had diameters ranging from 2.30 to as high as $4.60 \mu \mathrm{m}$. On average, the mean particle diameter was $1.79 \pm 1.30 \mu \mathrm{m}$. The surface of the spherical particles was smooth. Some smaller particles were fused together. Literature suggests the type of solute and its concentration and processing temperature and time influence the average sphere diameter [17,18,22]. While Yao et al. [18] focused on the synthesis and chemistry of the formation of carbon microspheres (hydrochar), Sevilla and Fuertres [17] investigated the chemical and structural properties of carbon microspheres made from hydrothermal carbonization of glucose, sucrose, and starch. They reported that the average diameter of carbon microspheres ranges from $0.6 \mu \mathrm{m}$ to $6.0 \mu \mathrm{m}$ and it depends on the type of saccharide (glucose $<$ starch $<$ sucrose) because each of them generates a different number of monomers as their individual crystal structure decomposes. For example, glucose is a monosaccharide, sucrose is disaccharide, and starch is a polysaccharide compound. Additionally, Sevilla and Fuertres [17] also reported that treatment at temperatures of 230 to $240{ }^{\circ} \mathrm{C}$ and short residence times $(0.5$ to $1 \mathrm{~h})$ results in fused peanut shaped hydrochar particles. While documenting the effect of concentration and residence time, Wang et al. [22] reported that the average diameter of sucrose hydrochar increased from $0.25 \mu \mathrm{m}$ for $0.15 \mathrm{~mol} / \mathrm{L}$ concentration to $5.0 \mu \mathrm{m}$ for $3.0 \mathrm{~mol} / \mathrm{L}$ concentration. They also reported that a concentration of $1.5 \mathrm{~mol} / \mathrm{L}$ sugar solution at reaction times of $1.0,2.0$, and $5.0 \mathrm{~h}$ produced hydrochar with average particle diameters of $1.0,2.5$, and $5.0 \mu \mathrm{m}$, respectively.

Figure 3. SEM pictures of (a) freeze-dried osmotic sugar solution (OS) (b) hydrochar made from OS through hydrothermal carbonization at $250{ }^{\circ} \mathrm{C}$ with $30 \mathrm{~min}$ of reaction time.

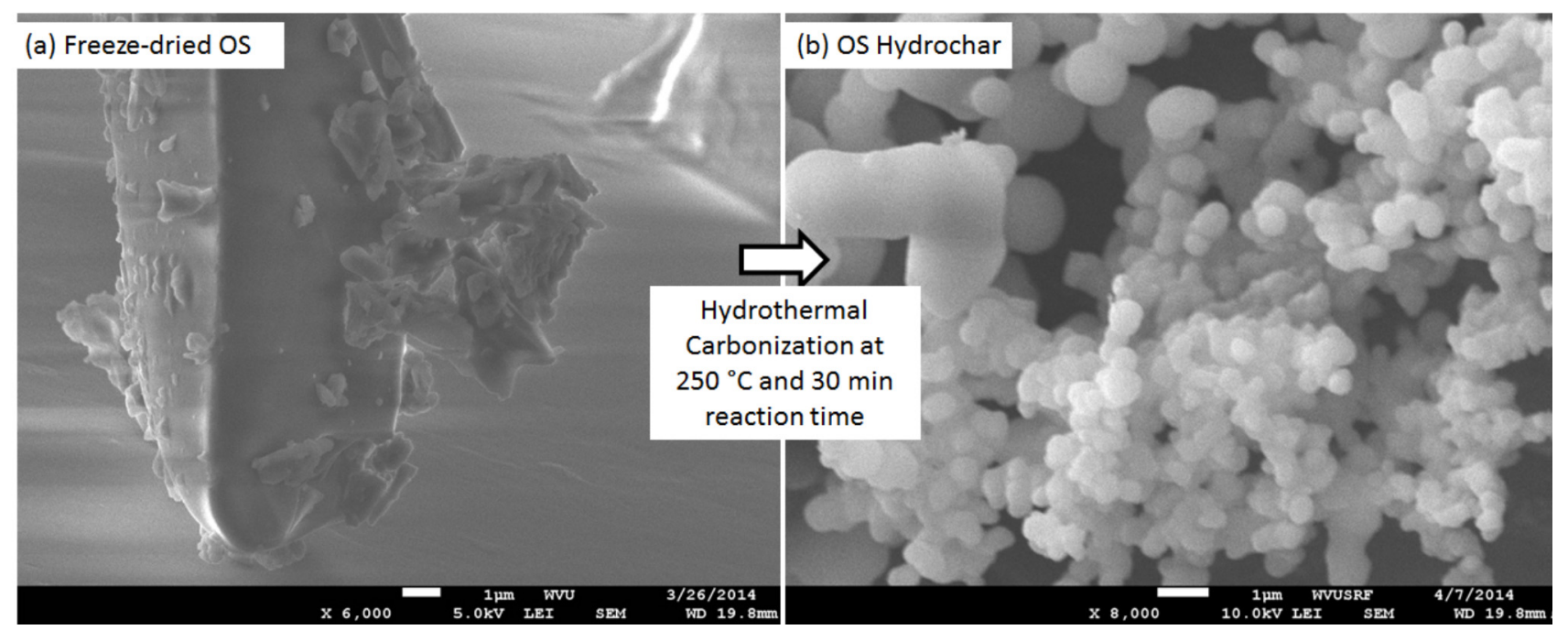

The BET surface area of devolatilized hydrochar made from OS was $16.62 \mathrm{~m}^{2} / \mathrm{g}$, which was much lower than $49.06 \mathrm{~m}^{2} / \mathrm{g}$ for the hydrochar produced from SOS (Table 6). Reported surface area for hydrochars made from glucose and sucrose solutions is $3 \mathrm{~m}^{2} / \mathrm{g}$ [17], which may increase to as high as $400 \mathrm{~m}^{2} / \mathrm{g}$ [22] when the hydrochar is further processed at $1000^{\circ} \mathrm{C}$ in an inert atmosphere. In an attempt to develop carbon microparticles with uniform nanopores as a possible precursor to molecular sieve 
carbon and anode material for Li-ion batteries, Wang et al. [22] performed hydrothermal carbonization of 0.5 to $3.0 \mathrm{~mol} / \mathrm{L}$ sugar solution at $190{ }^{\circ} \mathrm{C}$ for $5 \mathrm{~h}$. The hydrothermal carbonization process produced a black powder (hydrochar), which was further heated to $1000{ }^{\circ} \mathrm{C}$ in an argon atmosphere. The final product was uniform-diameter, hard-carbon microparticles with approximate diameters ranging from 0.25 to $5.0 \mu \mathrm{m}$. The average diameter increased from $0.25 \mu \mathrm{m}$ to $5.0 \mu \mathrm{m}$ with an increase in the initial sugar concentration from 0.5 to $1.5 \mathrm{~mol} / \mathrm{L}$. The microparticles had BET surface area of $400 \mathrm{~m}^{2} / \mathrm{g}$ with an average pore size of about $0.4 \mathrm{~nm}$. Additionally, the microparticles were able to reversibly store lithium up to $430 \mathrm{mAh} / \mathrm{g}$.

While hydrothermal carbonization of OS produced hydrochar with spherical particles, the SOS sample produced hydrochar with completely different structural characteristics (Figure 4). There was no definite shape of particles present in the SOS hydrochar, therefore, sphere diameters were not measured.

Figure 4. SEM pictures of (a) freeze-dried SOS sample (b) hydrochar made from SOS through hydrothermal carbonization at $250{ }^{\circ} \mathrm{C}$ with $30 \mathrm{~min}$ of reaction time.

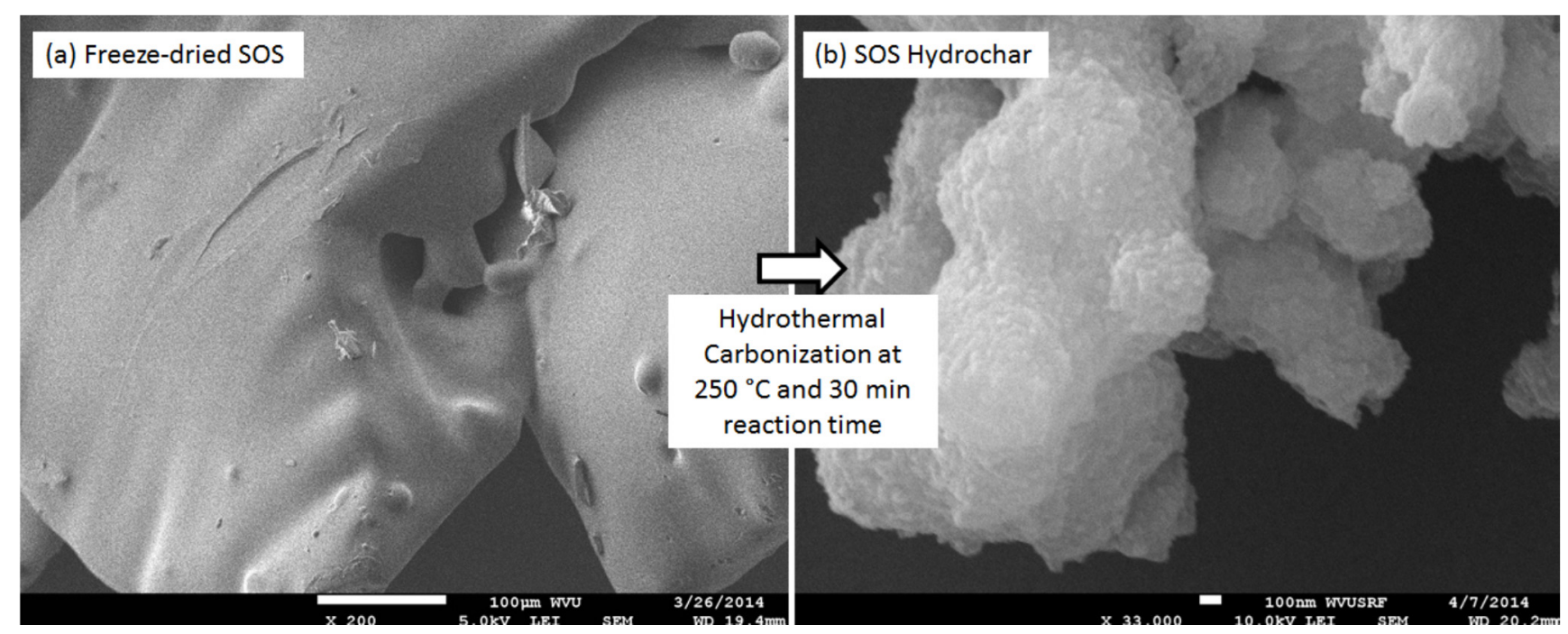

The surface of the SOS hydrochar was not smooth, and in fact, its surface was raspberry-like in appearance (Figure 4b). Differences in surface morphologies of the OS hydrochar and SOS hydrochar are consistent with the findings of Damir-Cakan et al. [23]. They processed glucose at the concentration of $10 \mathrm{w} / \mathrm{v} \%$ at $190{ }^{\circ} \mathrm{C}$ for $16 \mathrm{~h}$ with an addition of acrylic acid at four different ratios $(1,2,5$, and $10 \%$ (weight) with respect to total glucose concentration). According to their findings, surface morphology of hydrochar produced from glucose was influenced by the amount acrylic acid. While pure glucose solution produced spherical hydrochar particles with a smooth surface, addition of acrylic acid resulted in hydrochar particles with rough "raspberry" like surfaces. Damir-Cakan et al. [23] explained that, with the addition of acrylic acid, the hydrochar particles appeared to be formed out of small aggregated particles $(\sim 250 \mathrm{~nm})$. It appears that acrylic acid stabilizes the first-formed droplets, which further polymerize into micrometer-sized "raspberry" like structures. 


\section{Experimental Section}

The experimental procedures for procurement of materials to be tested, preparation of samples, freeze-drying, thermo-gravimetric analysis, hydrothermal treatment, and analytical characterization are detailed in the following sections.

\subsection{Materials and Sample Preparation}

Spent osmotic solutions (SOS) and one control osmotic solution (OS) were procured from an ongoing project of the National Science Foundation WVU (West Virginia University, Morgantown, WV, USA) ADVANCE Sponsorship Program on osmotic dehydration of blueberries. Frozen blueberries were purchased from the Oceana Foods, Inc. (Shelby, MI, USA). In this project, an osmotic solution with a sucrose (off-the-shelf sugar) concentration of $65^{\circ}$ Brix was prepared at WVU. The OS and blueberries were mixed at a fruit-to-solution ratio of $1: 3 \mathrm{~g} / \mathrm{g}$. To generate SOS, frozen blueberries were thawed to room temperature and then submerged in the osmotic solution for vacuum treatment. During this stage, a vacuum of $5 \mathrm{kPa}$ (1.5 inches of $\mathrm{Hg}$ or 50 mbar) was applied for $15 \mathrm{~min}$ before incubation. Following vacuum treatment, incubation of fruit and solution was carried out at $50{ }^{\circ} \mathrm{C}$ for $300 \mathrm{~min}$. After $300 \mathrm{~min}$, the SOS was separated from the partially dehydrated blueberries. In addition, unused OS was used as a control. The SOS and OS were each divided into two sets of sub-samples. One set of sub-sample was subjected to freeze-drying to prepare a dried powder for thermo-gravimetric analysis (TGA), Attenuated Total Reflectance Infrared (ATR-IR) Spectroscopy, and elemental analysis. Another set of sub-sample was used for hydrothermal carbonization to produce hydrochars.

\subsection{Thermo-Gravimetric Analysis}

The thermo-chemical decomposition behavior of the solid freeze-dried samples was assessed using a thermo-gravimetric analyzer (TGA) (Model: Q50, TA Instruments, Schaumburg, IL, USA). The TGA experiments were performed by heating approximately $8-12 \mathrm{mg}$ sample from 50 to $700{ }^{\circ} \mathrm{C}$ at three heating rates of 10,30 , and $50{ }^{\circ} \mathrm{C} / \mathrm{min}$ under a nitrogen flow of $50 \mathrm{~cm}^{3} / \mathrm{min}$. The TGA data (percent weight lost as function of temperature) were processed to generate a derivative curve (dtg: rate of fractional conversion as function of temperature) to identify various reaction zones. The TGA data were also used to calculate the activation energy for decomposition using the isoconversion method [35].

\subsection{Hydrothermal Carbonization}

Hydrothermal carbonization of the OS and SOS samples was performed by placing $50 \mathrm{~mL}$ pre-weighed liquid sample ( $\mathrm{m}_{\mathrm{feed}}$ ) inside a one-liter sealed pressure reactor (Model: 4500, Parr Instrument Company, Moline, IL, USA) at a constant stirrer speed (rpm) and zero cold nitrogen pressure as shown in Figure 5. The current model is not capable of logging stirrer rpm and changes in pressure. 
Figure 5. Experimental set-up for hydrothermal carbonization experiments.

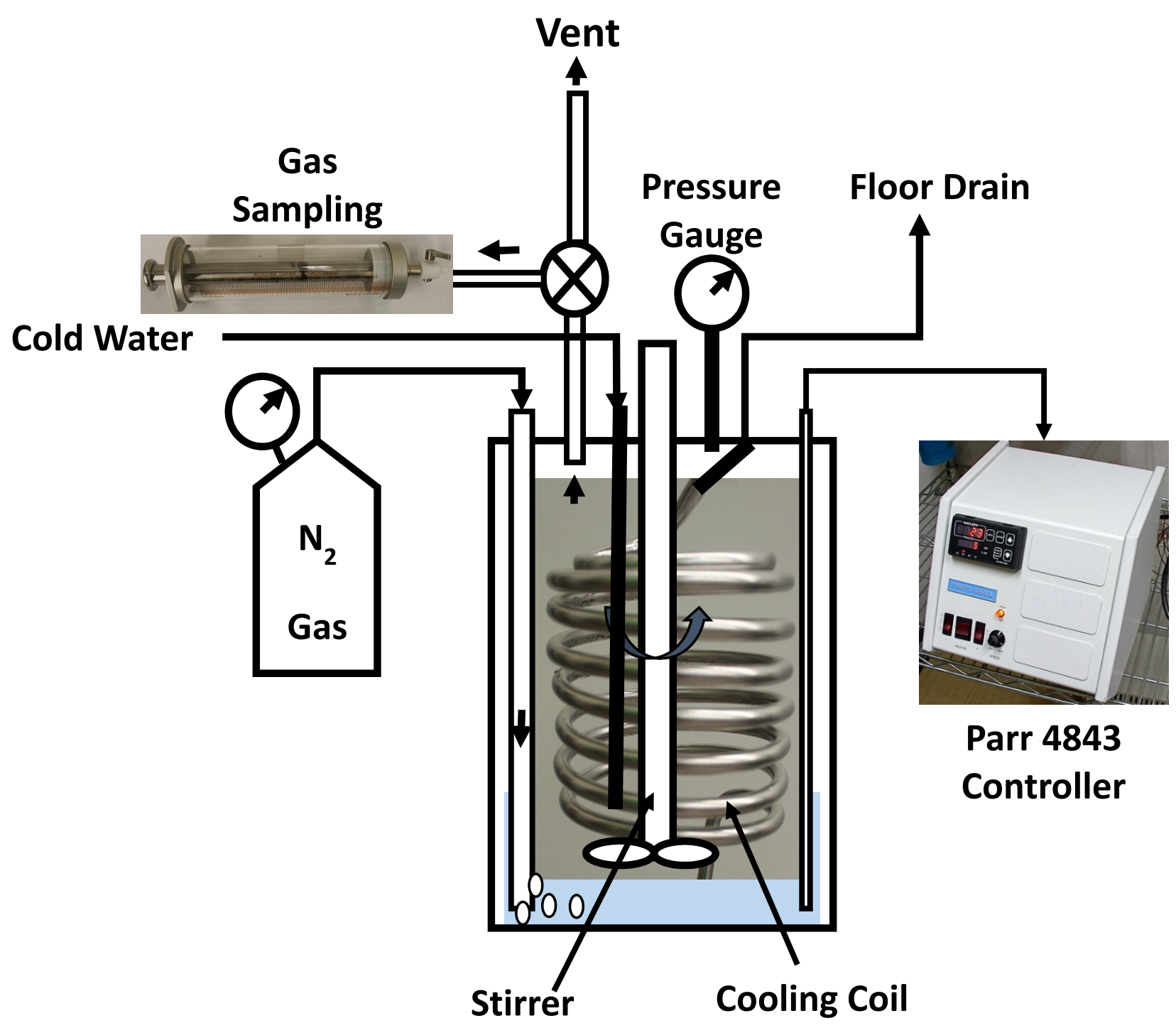

The difference in the weight of the empty reactor and the weight of the reactor with sample was used to calculate the actual sample weight. After that, the reactor was sealed, the weight of the sealed reactor was measured and air was removed from the headspace. To remove air from the sealed reactor, nitrogen gas was purged before the reaction for about $15 \mathrm{~min}$ to make sure that the gas composition in the reactor headspace was $99.5 \%$ nitrogen (verified from gas composition analysis). After that, the reactor was heated to $250{ }^{\circ} \mathrm{C}$ at the heating rate $10{ }^{\circ} \mathrm{C} / \mathrm{min}$, held at $250{ }^{\circ} \mathrm{C}$ for $30 \mathrm{~min}$, and then cooled to room temperature. After cooling, gasses from the reactor headspace were sampled by airtight syringes (Model: 1000 series, Hamilton, NV, USA), and analyzed by gas chromatography (Model: Clarus GC 580, Perk Elmer Waltham, MA, USA). Upon completely releasing the headspace gasses, the sealed reactor was reweighed (mslurry). The difference in the weight of the sealed reactor before and after heating accounted for the gases produced. After taking the weight, the reactor was opened and most of the contents of the reactor (hydrochar and some liquid) were collected and weighed on a drying pan. The drying pan with collected contents was placed inside an oven at $104{ }^{\circ} \mathrm{C}$ to evaporate the liquids. After $24 \mathrm{~h}$ of evaporation, the dried solid moisture-free hydrochar was weighed and the weight loss during the drying process was 
accounted for as the percent liquid content of the slurry (mliquid). This value was later used to calculate the product yields (hydrochar, liquid, and gas yields) on a wet-feed basis and on dry-feed matter basis. The product yields on a wet-feed basis were calculated as follows:

$$
\begin{gathered}
\text { Gas Yield }(\%, w . b .)=\frac{\left(m_{\text {feed }}-m_{\text {slurry }}\right)}{m_{\text {feed }}} \times 100 \\
\text { Liquid Yield }(\%, w . b .)=(100-\text { Gas Yield }) \times \frac{m_{\text {liquid }}}{100} \\
\text { Hydrochar Yield }(\%, w . b .)=100-\text { Gas Yield }- \text { Liquid Yield } \\
\text { Gas Yield }(\%, \text { d.b. })=\frac{\left(m_{\text {feed }}-m_{\text {slurry }}\right)}{m_{\text {dry-feed }}} \times 100 \\
\text { Hydrochar Yield }(\%, d . b .)=\frac{m_{\text {slurry }}\left(1-\frac{m_{\text {liquid }}}{100}\right)}{m_{\text {dry-feed }}} \times 100
\end{gathered}
$$

To calculate product yields on a dry-feed matter basis, the following equations were used:

Liquid Yield $(\%$, d.b. $)=100-$ Gas Yield - Hydrochar Yield

An example of calculation of product yields is given as follows: In an OS experiment, approximately, $59.40 \mathrm{~g}$ of feed sample ( $\left.\mathrm{m}_{\text {feed }}\right)$ was used, which contained $39.35 \mathrm{~g}$ soluble-solids (m $\mathrm{m}_{\text {dry-feed}}$ ) and remaining water $(20.05 \mathrm{~g})$. Hydrothermal carbonization reaction produced $53.10 \mathrm{~g}$ slurry (mslurry) and $6.30 \mathrm{~g}$ gaseous products ( $\mathrm{m}_{\text {slurry }}-\mathrm{m}_{\text {feed }}$ ). The slurry, upon oven drying, resulted on $51.54 \%$ moisture (mliquid). Therefore, the hydrochar, liquid, and gas yields, on wet-feed basis, are calculated to be $43.32 \%, 46.07 \%$, and $10.61 \%$, respectively. In addition, the hydrochar, liquid, and gas yields, on dry-feed matter basis, are calculated to be $65.39 \%, 18.61 \%$, and $16.01 \%$, respectively.

The hydrochar was tested for elemental composition, proximate analysis, Brunauer-Emmett-Teller (BET) surface area and scanning electron microscopy (SEM). It is important to mention that the $250{ }^{\circ} \mathrm{C}$ reaction temperature and $30 \mathrm{~min}$ holding time was selected after reviewing the literature [17,21-23]. Sevilla [17] has reported using holding times of $4.5 \mathrm{~h}$ for $190{ }^{\circ} \mathrm{C}, 1.0 \mathrm{~h}$ for $230^{\circ} \mathrm{C}$, and $0.5 \mathrm{~h}$ for $240{ }^{\circ} \mathrm{C}$. Wang [22] used a holding time of $5 \mathrm{~h}$ for $190^{\circ} \mathrm{C}$ and Demir-Cakan [23] had performed experiments at $150{ }^{\circ} \mathrm{C}$ with $16 \mathrm{~h}$ holding times. Therefore, literature suggested holding times of $30 \mathrm{~min}$ might be used for high reaction temperature $\left(250^{\circ} \mathrm{C}\right)$.

\subsection{Analytical Characterization}

The OS and SOS were characterized for $\mathrm{pH}$ and total solids. The $\mathrm{pH}$ was measured using a $\mathrm{pH}$ meter (Model: AB15, Fisher Scientific, USA). To measure total solids, a known amount of sample was evaporated in a drying oven at $104{ }^{\circ} \mathrm{C}$ for $24 \mathrm{~h}$. In addition, the OS and SOS were tested for chemical functional groups and elemental composition. The analysis of the chemical functional groups was performed using Attenuated Total Reflectance Infrared (ATR-IR) Spectroscopy (Model: Nicolet iS10 Smart iTR, Thermo Scientific). The elemental composition was measured using a CHNS analyzer (Model: Series II CNHS/O Analyzer 2400, PerkinElmer, Waltham, MA, USA). The elemental composition was used in an empirical equation to determine the higher heating value (HHV) of the 
samples [31]. In addition, proximate analysis (moisture, volatile matter, fixed carbon and ash) was carried out using a proximate analyzer (Model: LECO TGA 701, LECO Corporation, St. Joseph, MI, USA) following the ASTM D3174 standard [36]. Scanning Electron Microscopy was performed on a JEOL JSM-7600F Scanning Electron Microscope (Peabody, MA). The SEM sputter had a target of Gold/Palladium $(60 \% / 40 \%)$ and the chamber was maintained under a vacuum of $9.6 \times 10^{-5} \mathrm{~Pa}$. Several SEM images with spherical particles of hydrochar were printed and spherical particles were numbered on the printed pictures. After that, the diameter of each numbered particle was manually measured with fifty spherical particles constituting the measured set. Brunauer-Emmett-Teller (BET) surface area was measured for the devolatilized hydrochars with nitrogen using a surface area analyzer (Model: ASAP 2020: Surface Area and Porosity Analyzer, Norcross, GA, USA). Devolatilization of hydrochars was performed by heating the hydrochars in the crucibles of the LECO TGA 701 up to $600{ }^{\circ} \mathrm{C}$ for 30 min under nitrogen. During BET surface area measurements, the samples were degassed at $300{ }^{\circ} \mathrm{C}$ under a vacuum for $12 \mathrm{~h}$.

\subsection{Statistical Experiment Design}

Two treatments OS and SOS were used in a completely randomized experimental design with three replications. There were a total of six hydrothermal experiments performed.

\section{Conclusions}

In this paper, OS and SOS samples were characterized for their thermo-chemical decomposition behavior and for hydrothermal carbonization as a means of generating experimental data to develop a hydrothermal treatment to produce value-added hydrochar. SOS and OS were different in terms of total solid content and acidity ( $\mathrm{pH}$ value). OS had a total solid content of $66.25 \%$ and a $\mathrm{pH}$ of 6.61 while SOS had total solid content of $59.00 \%$ and a $\mathrm{pH}$ of 3.61 .

Thermo-gravimetric experiments showed that the SOS sample lost 3.86, 28.66, 30.90, and 13.66\% (weight) in the temperature zones of $120-160{ }^{\circ} \mathrm{C}$; $180-250{ }^{\circ} \mathrm{C}, 250-350{ }^{\circ} \mathrm{C}$, and $350-600{ }^{\circ} \mathrm{C}$, respectively. In contrast, the OS sample showed weight loss of $0.18,18.76,47.29$, and $14.18 \%$ (weight), respectively in the same temperature zones. Derivative thermo-gravimetric results showed that the spent osmotic solutions had one extra decomposition peak at $130^{\circ} \mathrm{C}$ due to decomposition of antioxidants. In addition, both samples had two fixed peaks at 225 and $280^{\circ} \mathrm{C}$. The only difference between the SOS and OS in peaks was that the $225^{\circ} \mathrm{C}$ peak was larger in the SOS due to the presence of higher amounts of non-sucrose sugars.

In addition, both samples produced, approximately, $40 \%-42 \%$ (on wet-feed basis) hydrochar with atomic $\mathrm{O} / \mathrm{C}$ and $\mathrm{H} / \mathrm{C}$ contents of 0.25 and 1.04, respectively. Both hydrochars had a higher heating value of approximately $30 \mathrm{MJ} / \mathrm{kg}$; however, the hydrochar produced from the SOS sample had higher BET surface area $\left(49.06 \mathrm{~m}^{2} / \mathrm{g}\right)$ than that produced from the OS sample $\left(16.62 \mathrm{~m}^{2} / \mathrm{g}\right)$. In addition, the OS sample produced a hydrochar composed of smooth-surfaced spherical particles of $1.79 \pm 1.30 \mu \mathrm{m}$ diameter whereas the SOS sample produced hydrochar particles with no definite shape but with a raspberry like surface. 


\section{Implications}

The results presented in this paper have broad technical and economic implications for the fruit dehydration industry. For example, anaerobic digestion is the most prevalent method for waste treatment to meet effluent requirements of reduced BOD and TSS. Food-dehydration systems are currently regulated for liquid waste disposal and very soon, all of them will be subjected to regulations for greenhouse gas emission. In some cases, fruit processing capacity is limited by the regulatory limitation for BOD, which is $1.86,1.12$, and $0.8 \mathrm{~kg} / 1000 \mathrm{~kg}$ of fruit processed daily, monthly and yearly maximum, respectively, after utilizing the best wastewater treatment. The fruit-dehydration industry cannot operate without wastewater treatment because with the current processing methods, it generates approximately $1.91 \mathrm{~kg}$ BOD for every $\mathrm{kg}$ of fruit (apples) processed, just from SOS. Extrapolating this number, a medium-sized processing plant $(\leq 10,000$ ton/year processing capacity) would generate BOD of 19.1 tons per year, which must be reduced to 8.0 tons per year of operation. Discharging 19.1 tons of BOD without wastewater treatment would require the addition of approximately 168 billion gallons of water every year (based on $30 \mathrm{mg} / \mathrm{L}$ effluent limitation given in Table 1). However, after wastewater treatment (combination of processes- physical, chemical, and biological treatment) $[5,6]$ this dilution would require, under current practices, only 0.16 billion gallons of water every year. If practical data are to be considered, the state of Michigan processes 263,000 tons apples, 17,000 tons of cherries, and 24,300 tons of blueberries every year [37], which generates 3.4, 1.3, and 0.22 billion gallons of wastewater every year, respectively. These numbers include the fruit dehydration industry. It is expected that the BOD requirement due to SOS will be reduced to zero with the proposed hydrothermal carbonization process, thereby, saving billions of gallons of water required for dilution and the cost associated with the wastewater treatment in addition to the reduction in environmental pollution/GHG emissions.

Wastewater treatment has associated costs as presented by the EPA [5], which are 7.1, 31.1, 48.2, $120,17.8$, and 5 cents per 1000 gallons for flow measurement and screening, neutralization of the aerated lagoon, activated sludge with sludge concentration, filtration, and chlorination, respectively. Therefore, a wastewater treatment plant using all of these operations will cost $\$ 2.29$ (in 1975) per 1000 gallons, which would be approximately $\$ 10$ in the year 2014 after adjusting for inflation. This translates into $\$ 49.2$ million spent by the state of Michigan fruit processors on wastewater treatment operations. It is expected that the proposed technology would not only eliminate most of this cost but it will also generate hydrochar and carbon microparticles, a value-added sequestered carbon. Additionally, hydrothermal carbonization would capture at least $46 \%$ [17] and at most, 75\% [19] of the carbon present in the feedstock, which would translate into saving nearly 1.26 million tons of $\mathrm{CO}_{2}$ every year. This calculation is based on $2.74 \mathrm{~kg}$ fructose in SOS $/ \mathrm{kg}$ of apples, 10,000 tons production capacity, and 75\% carbon capture through hydrothermal carbonization. Therefore, it is expected that the hydrothermal treatment of SOS will enhance sustainability of osmotic dehydration of fruits by saving billions of gallons of freshwater needed for BOD dilution, savings in cost of wastewater treatment, and savings in millions of tons of greenhouse gas emissions. 


\section{Acknowledgments}

Authors would like to acknowledge partial funding support from a project funded through National Science Foundation's (NSF) ADVANCE IT Program under Award HRD-1007978 and the United States Department of Agriculture (USDA) McStennis Grant Program to carry out this research. Any opinions, findings, and conclusions or recommendations expressed in this material are those of the authors and do not necessarily reflect the views of the NSF and the USDA. In addition, the authors acknowledge Wenjia Jin, a graduate student, for performing TGA, hydrothermal, and most of the analytical experiments; Alexandra Smith, a graduate student, for generating SOS and performing SEM characterization; Sarah Beamer, a Research Technician, for conducting freeze-drying; Jonathan Yancey, a graduate student, for performing BET analysis; and Ipsita Tingi, a 8th grader at Suncrest Middle School for measuring particle diameter. The authors also acknowledge John Zondlo, Department of Chemical Engineering for reviewing and proofreading this manuscript.

\section{Author Contributions}

Kaushlendra Singh, Principal Investigator of the USDA-McStennis grant, is responsible for designing the experiments, supervising experimental work, data analysis, writing the manuscript, and communicating with the journal.

Litha Sivanandan, Principal Investigator of the project funded through National Science Foundation WVU ADAVANCE grant is responsible for supervising experiments related to OS and SOS generation and providing key discussion on results related to it.

\section{Conflicts of Interest}

The authors declare no conflict of interest.

\section{References}

1. Dalla Rosa, M.; Giroux, F. Osmotic treatments (OT) and problems related to the solution management. J. Food Eng. 2001, 49, 223-236.

2. Fito, P.; Chiralt, A.; Barat, J.M.; Martinez-Monzo, J. Vacuum impregnation in fruit processing. In Trends in Food Engineering; Lozano, J.E., Anon, C., Barbosa-Cánovas, G.V., Parada-Arias, E., Eds.; Technomic Publishing Company, Inc.: Lancaster, PA, USA, 2000; pp. 149-150.

3. Aachary, A.A.; Prapulla, S.G. Value addition to spent osmotic sugar solution (SOS) by enzymatic conversion to fructooligosaccharides (FOS), a low calorie prebiotic. Innov. Food Sci. Emerg. Technol. 2009, 10, 284-288.

4. Torreggiani, D.; Bertolo, G. Present and future in process control and optimization of osmotic dehydration: From unit operation to innovative combined process: An overview. In Advances in Food and Nutrition Research; Academic Press: San Diego, CA, USA, 2004; Volume 48, pp. 173-238.

5. EPA. Pollution Abatement in the Fruit and Vegetable Industry-Wastewater Treatment, EPA-625/3-77-0007; US Environmental Protection Agency Region 5: Chicago, IL, USA, 1977. 
6. Granholm, J.M.; Chester, S.E. Michigan Fruit and Vegetable Processor's Guide to Environmental Regulations; Michigan Department of Environmental Quality: Lansing, MI, USA, 2007.

7. Juliana, P.; Raquel, D.; Julian, M. Extraction of phenolic compounds from blueberry (Vaccinium myrtillus L.) residues using supercritical $\mathrm{CO}_{2}$ and pressurized water. In Proceedings of the III Iberoamerican Conference on Supercritical Fluids, Cartagena, Columbia, 1-5 April 2013.

8. Lee, J.; Wrolstad, R.E. Extraction of anthocyanins and polyphenolics from blueberry processing waste. J. Food Sci. 2004, 69, 564-573.

9. Nicoué, E.É.; Savard, S.; Belkacemi, K. Anthocyanins in wild blueberries of quebec: Extraction and identification. J. Agric. Food Chem. 2007, 55, 5626-5635.

10. American Society of Agricultural and Biological Engineers. Terminology and Definitions for Biomass Production, Harvesting and Collection, Storage, Processing, Conversion and Utilization; ANSI/ASABES593.1; American Society of Agricultural and Biological Engineers: St. Joseph, MI, USA, 2011.

11. Gupta, R.B.; Kumar, S.; Kong, L. Biomass to Biochar Conversion in Subcritical Water. US20110179703 A1, 28 July 2011.

12. Libra, J.; Kyoung, S.R.; Kammann, C.; Funke, A.; Berge, N.; Neubauer, Y.; Titirici, M.; Fühner, C.; Bens, O.; Kern, J.; et al. Hydrothermal carbonization of biomass residuals: A comparative review of the chemistry, processes and applications of wet and dry pyrolysis. Biofuels 2011, 2, 71-106.

13. Funke, A.; Ziegler, F. Hydrothermal carbonization of biomass: A summary and discussion of chemical mechanisms for process engineering. Biofuels Bioprod. Biorefining 2010, 4, 160-177.

14. Wiboonsirikul, J.; Adachi, S. Extraction of functional substances from agricultural products or by-products by subcritical water treatment. Food Sci. Technol. Res. 2008, 14, 319-328.

15. Toor, S.S.; Rosendahl, L.; Rudolf, A. Hydrothermal liquefaction of biomass: A review of subcritical water technologies. Energy 2011, 36, 2328-2342.

16. López Barreiro, D.; Prins, W.; Ronsse, F.; Brilman, W. Hydrothermal liquefaction (htl) of microalgae for biofuel production: State of the art review and future prospects. Biomass Bioenergy 2013, 53, 113-127.

17. Sevilla, M.; Fuertes, A.B. Chemical and structural properties of carbonaceous products obtained by hydrothermal carbonization of saccharides. Chemistry 2009, 15, 4195-4203.

18. Yao, C.; Shin, Y.; Wang, L.-Q.; Windisch, C.F.; Samuels, W.D.; Arey, B.W.; Wang, C.; Risen, W.M.; Exarhos, G.J. Hydrothermal dehydration of aqueous fructose solutions in a closed system. J. Phys. Chem. C 2007, 111, 15141-15145.

19. Berge, N.D.; Ro, K.S.; Mao, J.; Flora, J.R.V.; Chappell, M.A.; Bae, S. Hydrothermal carbonization of municipal waste streams. Environ. Sci. Technol. 2011, 45, 5696-5703.

20. Shanableh, A. Production of useful organic matter from sludge using hydrothermal treatment. Water Res. 2000, 34, 945-951.

21. Sahu, S.; Behera, B.; Maiti, T.K.; Mohapatra, S. Simple one-step synthesis of highly luminescent carbon dots from orange juice: Application as excellent bio-imaging agents. Chem. Commun. 2012, $48,8835-8837$.

22. Wang, Q.; Li, H.; Chen, L.; Huang, X. Monodispersed hard carbon spherules with uniform nanopores. Carbon 2001, 39, 2211-2214. 
23. Demir-Cakan, R.; Baccile, N.; Antonietti, M.; Titirici, M.-M. Carboxylate-rich carbonaceous materials via one-step hydrothermal carbonization of glucose in the presence of acrylic acid. Chem. Mater. 2009, 21, 484-490.

24. Sun, X.; Li, Y. Colloidal carbon spheres and their core/shell structures with noble-metal nanoparticles. Angew. Chem. Int. Ed. 2004, 43, 597-601.

25. Sun, X.; Li, Y. Ag/C core/shell structured nanoparticles: Controlled synthesis, characterization, and assembly. Langmuir 2005, 21, 6019-6024.

26. Yu, S.H.; Cui, X.J.; Li, L.L.; Li, K.; Yu, B.; Antonietti, M.; Cölfen, H. From starch to metal/carbon hybrid nanostructures: Hydrothermal metal-catalyzed carbonization. Adv. Mater. 2004, 16, 1636-1640.

27. Qian, H.-S.; Yu, S.-H.; Luo, L.-B.; Gong, J.-Y.; Fei, L.-F.; Liu, X.-M. Synthesis of uniform Te/Carbon-rich composite nanocables with photoluminescence properties and carbonaceous nanofibers by the hydrothermal carbonization of glucose. Chem. Mater. 2006, 18, 2102-2108.

28. Wang, W.; Xiong, S.; Chen, L.; Xi, B.; Zhou, H.; Zhang, Z. Formation of flexible Ag/C coaxial nanocables through a novel solution process. Cryst. Growth Des. 2006, 6, 2422-2426.

29. Gong, J.-Y.; Yu, S.-H.; Qian, H.-S.; Luo, L.-B.; Li, T.-W. Pva-assisted hydrothermal synthesis of Copper/Carbonaceous submicrocables: Thermal stability, and their conversion into amorphous carbonaceous submicrotubes. J. Phys. Chem. C 2007, 111, 2490-2496.

30. Zhang, Z.; Hao, J.; Zhang, J.; Zhang, B.; Tang, J. Protein as the source for synthesizing fluorescent carbon dots by a one-pot hydrothermal route. RSC Adv. 2012, 2, 8599-8601.

31. Channiwala, S.A.; Parikh, P.P. A unified correlation for estimating HHV of solid, liquid and gaseous fuels. Fuel 2002, 81, 1051-1063.

32. Tipson, R.S. Infrared Spectroscopy of Carbohydrates, a Review of the Literature; Institute for Materials Research, National Bureau of Standards Monograph 110: Washington, DC, USA, 1998; p. 110.

33. Pappas, C.S.; Takidelli, C.; Tsantili, E.; Tarantilis, P.A.; Polissiou, M.G. Quantitative determination of anthocyanins in three sweet cherry varieties using diffuse reflectance infrared fourier transform spectroscopy. J. Food Compos. Anal. 2011, 24, 4.

34. Khanal, R.C.; Howard, L.R.; Prior, R.L. Effect of heating on the stability of grape and blueberry pomace procyanidins and total anthocyanins. Food Res. Int. 2010, 43, 1464-1469.

35. Jin, W.; Singh, K.; Zondlo, J. Pyrolysis kinetics of physical components of wood and wood-polymers using isoconversion method. Agriculture 2013, 3, 12-32.

36. ASTM. Astm Standards d 3174: Standard Test Method for Ash in the Analysis Sample of Coal and Coke from Coal; American Society for Testing and Materials: Philadelphia, PA, USA, 2003.

37. Safferman, S.; Wright, T.; Miller, S.; Higginbotham, A. Wastewater Characteristics and Quantities Associated with Fruit and Vegetable Processing in Michigan; Michigan State University: East Lansing, MI, USA, 2007.

(C) 2014 by the authors; licensee MDPI, Basel, Switzerland. This article is an open access article distributed under the terms and conditions of the Creative Commons Attribution license (http://creativecommons.org/licenses/by/4.0/). 